\title{
Tocilizumab Treatment Reduces Mortality in Hospitalized Patients with COVID-19
}

\section{Merjona Saliaj, MD, MPH}

Icahn School of Medicine at Mount Sinai / New York City Health + Hospitals/Queens, New York, USA

Matthew Li, PharmD, BCPS, BCCCP

Icahn School of Medicine at Mount Sinai / New York City Health + Hospitals/Queens, New York, USA

Vincent Rizzo, MD, MBA

Icahn School of Medicine at Mount Sinai / New York City Health + Hospitals/Queens, New York, USA

Mahmoud Nassar, MD, PhD ( $\sim$ dr.nassar@aucegypt.edu )

Icahn School of Medicine at Mount Sinai / New York City Health + Hospitals/Queens, New York, USA https://orcid.org/0000-0002-5401-9562

Nso Nso, MD, MPH

Icahn School of Medicine at Mount Sinai / New York City Health + Hospitals/Queens, New York, USA

Zarwa Idrees, MD

Icahn School of Medicine at Mount Sinai / New York City Health + Hospitals/Queens, New York, USA

Luis A. Medina, MD

Icahn School of Medicine at Mount Sinai / New York City Health + Hospitals/Queens, New York, USA

Anastasia Novikov, MD

Icahn School of Medicine at Mount Sinai / New York City Health + Hospitals/Queens, New York, USA

Salim Yaghi, MD

Icahn School of Medicine at Mount Sinai / New York City Health + Hospitals/Queens, New York, USA

Francisco J. Cuevas, MD

Icahn School of Medicine at Mount Sinai / New York City Health + Hospitals/Queens, New York, USA

Carolyn M. Salafia, MD, Msci

Icahn School of Medicine at Mount Sinai / New York City Health + Hospitals/Queens, New York, USA

Hamid Razaki, PharmD, BCPS

Icahn School of Medicine at Mount Sinai / New York City Health + Hospitals/Queens, New York, USA

Charles Berman, MD

Icahn School of Medicine at Mount Sinai / New York City Health + Hospitals/Queens, New York, USA

Issac Sachmechi, MD

Icahn School of Medicine at Mount Sinai / New York City Health + Hospitals/Queens, New York, USA Theo Trandafirescu, MD

Icahn School of Medicine at Mount Sinai / New York City Health + Hospitals/Queens, New York, USA Debra Brennessel, MD

Icahn School of Medicine at Mount Sinai / New York City Health + Hospitals/Queens, New York, USA 


\section{George T. Martin, MD}

Icahn School of Medicine at Mount Sinai / New York City Health + Hospitals/Queens, New York, USA Jazila Mantis, MD

Icahn School of Medicine at Mount Sinai / New York City Health + Hospitals/Queens, New York, USA

\section{Research Article}

Keywords: Tocilizumab, mortality, mechanical ventilation, CRP, IL-6, oxygen saturation

Posted Date: July 27th, 2021

DOI: https://doi.org/10.21203/rs.3.rs-752079/v2

License: (c) (i) This work is licensed under a Creative Commons Attribution 4.0 International License.

Read Full License 


\section{Abstract}

Aims This study aimed to investigate the potential of tocilizumab therapy in minimizing mortality and mechanical ventilation (MV) requirements among hospitalized COVID-19 patients.

Methods A single-center, retrospective, observational cohort study of 375 patients with severe COVID-19 (March 1 and April 22, 2020) included 150 patients treated with Tocilizumab and 225 consecutive control patients adjusted for age and gender. Both groups received concomitant standard of care treatments in addition to Tocilizumab. The statistical methods relied on survival analyses, conditional logistic regression models, and contingency analyses. The primary outcomes included in-hospital mortality and the MV requirement.

Results Tocilizumab associated with improved in-hospital mortality ( $34.7 \%$ vs $46.7 \%, P=0.0136)$ and lower requirement for $M V$ on days 1,3 , and 5 after treatment $(P=0.005, P<0.0001$, and $P=0.0021$, respectively). Lower mortality was observed if tocilizumab was administered within 48 hours after admission $(P=0.0226)$. Older age and low blood oxygen saturation on admission decreased the odds of survival $(P<0.005)$.

Conclusion Our study demonstrates a significant reduction in mortality and decreased requirement of MV with tocilizumab treatment in addition to the standard of care. Early administration of Tocilizumab within 48 hours reduces the risk of mortality.

\section{Highlights}

- Tocilizumab was associated with improved in-hospital mortality.

- Tocilizumab lowers mechanical ventilation (MV) requirements on days 1,3 , and 5 after treatment.

- Lower mortality was observed with administration of tocilizumab within 48 hours after admission.

\section{Introduction}

Coronavirus disease 2019 (COVID-19), caused by severe acute respiratory syndrome coronavirus 2 (SARS-CoV-2), emerged from Wuhan, China (in December 2019), with the first case identified in the United States in January 2020[1]. The steadfast global expansion of the COVID-19 pandemic has created an urgent need for effective evidence-based therapies.

A mounting body of evidence suggests that a subgroup of patients with SARS-CoV-2 may deteriorate clinically due to a proinflammatory cytokine storm syndrome [2, 3]. An overwhelming release of cytokines such as interleukin-6 (IL-6), tumor necrosis factor-alpha, interleukin-12, and interleukin-1[4] leads to an increase in alveolar exudate, acute respiratory distress syndrome (ARDS), and multiorgan dysfunction $[5,6]$. Tocilizumab is a recombinant humanized monoclonal antibody against IL-6 receptors. It is used for the treatment of a variety of diseases such as rheumatoid arthritis (RA), giant cell arteritis, 
and cytokine release syndrome in patients treated with T-cell engaging therapies[7-9]. Initial data from China reported the resolution of pyrexia, decreased oxygen requirements, improved radiologic findings, and reduced inflammatory markers by day five after therapy with tocilizumab[10]. The published data supporting the use of Tocilizumab for COVID-19 management is currently inconclusive [10-13]. The purpose of this study was to evaluate the effect of tocilizumab therapy on the clinical outcomes of COVID-19 patients.

\section{Methods}

\section{Study Population}

We conducted a single-center, retrospective, observational cohort study at the New York City Health + Hospitals/Queens, an inner-city, safety-net community teaching hospital in New York City. The patients with a laboratory-confirmed positive SARS-CoV-2 nasopharyngeal swab via polymerase chain reaction (PCR) test admitted between March 1, 2020, and April 22, 2020, were screened for their inclusion in the study. The control cohort consisted of patients admitted before April 3, 2020, when tocilizumab was not yet available at our facility. The standard of care included supplemental oxygen, hydroxychloroquine, azithromycin, therapeutic anticoagulation, and glucocorticoids. On April 3, 2020, off-label tocilizumab was offered in addition to the standard of care to treat COVID-19 patients who met institution-specific eligibility criteria (e-Eligibility in Supplement 1 ). The respiratory disease severity, an ordinal scale, was developed based on oxygen requirements, mode of oxygen delivery, and mechanical ventilation (MV). It included 5 categories; 0 (no oxygen requirement), 1 (oxygen delivery via nasal cannula for saturation less than 94\%), 2 (oxygen delivery via non-rebreather/OxyMask), 3 (oxygen delivery via noninvasive MV), and 4 (invasive MV) (e-Methods in Supplement 1).

The patients were excluded from the study if they had a contraindication to Tocilizumab [14], expired within 48 hours of admission, or were transferred to another facility without a unified electronic medical record.

The tocilizumab group was randomized in a 1:2 ratio to the control cohort adjusted for age and gender. The Icahn School of Medicine at Mount Sinai and New York City Health and Hospitals/Queens Institutional Review Board approved this study after obtaining a waiver for informed consent.

\section{Tocilizumab Treatment}

The tocilizumab treatment group received an intravenous dose of Tocilizumab $400 \mathrm{mg}$ with an optional second dose of $400 \mathrm{mg}$ or $8 \mathrm{mg} / \mathrm{kg}$ weight-based dose 12 hours later. The tocilizumab and control groups received the standard of care, including optimal treatment with supplemental oxygen if oxygen saturation was $<94 \%$ on room air. The standard therapy included hydroxychloroquine[15] with a loading dose of $400 \mathrm{mg}$ twice daily for the first day followed by $200 \mathrm{mg}$ twice daily for the remaining 4 days, azithromycin with a loading dose of $500 \mathrm{mg}$ followed by $250 \mathrm{mg}$ daily for a total of 5 days, anticoagulation[16], and systemic corticosteroids[15, 17, 18]. 


\section{Outcomes}

The primary outcome was COVID-19-related in-hospital mortality, while the secondary outcomes included the requirement of invasive MV, severity of respiratory disease, hospital length of stay (LOS), intensive care unit (ICU), LOS, and safety outcomes. The safety outcomes included anaphylaxis, injection site reactions, increased serum transaminases greater than 3-folds (the normal upper limit), and a positive QuantiFERON test. The commonly reported COVID-19 complications, including acute stroke, thromboembolic events, and atrial fibrillation with a rapid ventricular response, were categorically recorded. The thromboembolic events were further evaluated in the context of IL- 6 elevations for the patients on tocilizumab therapy. The authors also compared thromboembolic events with deaths and IL6 levels of the tocilizumab group patients. They used a line chart to evaluate the oxygen requirements of mechanically ventilated patients on tocilizumab with corticosteroid therapies.

\section{Statistical Analysis}

The continuous data were first assessed for normality using the Shapiro-Wilk test. In all cases, the outcome was negative, and thus non-parametric tests were used to assess continuous numeric data. Next, the dichotomous outcomes were analyzed with Fisher's Exact Test. The multivariate logistic regression analyses were performed using the variables (outlined in Table 2) with survival as the dependent attribute. The non-significant variables were removed in a backward stepwise process until only significant variables remained in the model. The survival analysis (time to event) was performed to produce Kaplan-Meier curves using in-hospital mortality as the "event." The data were censored for those patients who survived or whose outcomes were unknown after hospital discharge. All statistical analyses were performed with SAS Studio and JMP software (Cary, NC, USA). The authors developed stacked bar charts for biologically analyzing the patterns of IL-6 levels, thromboembolic events, and deaths among patients with tocilizumab therapy. They also evaluated the variations in the CRP levels of Tocilizumab therapy patients with thromboembolic events.

\section{Results}

After applying exclusion criteria, 150 patients treated with tocilizumab and 225 control patients were included in the study analysis. The demographic and baseline characteristics are described in Table 1. The median age was 62.5 years (IQR $53-71$ ) for the tocilizumab group and 64 years $(54-73)$ for the control group. The tocilizumab group had fewer observed medical comorbidities compared to the control group, significant for congestive heart failure $(2.7 \%$ vs $10.7 \%, P<0.005)$, diabetes mellitus ( $38.7 \%$ vs $51.1 \%, P=0.02)$, and smoking history $(2.0 \%$ and $10.2 \%, P<0.005)$. The overall BMI was similar in both groups.

The increase in inflammatory markers at baseline was observed in both groups (Table 1). The concomitant therapies used in our cohort are summarized in (Table 1). Most of our patients in tocilizumab and control groups received hydroxychloroquine $(92.7 \%$ and $89.8 \%$ ) and azithromycin (92.7 $\%$ and $92.8 \%)$. Tocilizumab was initiated at a median of 1 day $(\mathrm{Q} 1-\mathrm{Q} 3,1-3)$ following admission, while the 
standard of care (hydroxychloroquine and azithromycin) was provided at a median of 0 days (Q1-Q3, 01).

\section{Secondary outcomes}

The treatment with tocilizumab led to a significant decrease in the $\mathrm{MV}$ requirement for treatment group compared to the control group after day $1(P=0.0005)$, day $3(P<0.0001)$ and day $5(P=0.002)$. The tocilizumab group reportedly experienced a longer median hospital LOS (10 vs 7 days, $P=0.0002$, MannWhitney). There were no observed differences in ICU LOS ( 9 vs 6 days, $P=0.079$ ) or duration of MV ( 8 vs 5.5 days, $P=0.442$ ). There was a transient increase of liver enzymes up to 3 -fold in 22 of the tocilizumabtreated patients within 5 days post-treatment. No anaphylactic or injection site reactions were reported.

\section{Logistic Regression Analyses}

The logistic regression analyses show P-values, odds ratios, and their $95 \%$ confidence limits are summarized in Table 2. For the entire cohort of 375 patients, the blood oxygen saturation level was the strongest predictor of survival $(P<0.001)$. This remained true for the group not treated with Tocilizumab $(P<0.001)$. The age was also a strong predictor $(P=0.019)$ for the entire population; however, within the tocilizumab group analyses, age $(P=0.007)$ surpassed the blood oxygen saturation level $(P=0.010)$ as a significant predictor of survival. The BMI was not a significant predictor of survival in any of the study groups. Asthma was a predictive factor of survival for the entire cohort $(\mathrm{OR}=2.61,95 \% \mathrm{Cl} 1.11-6.12, \mathrm{P}=$ $0.022)$ including the tocilizumab group $(\mathrm{OR}=11.00,95 \% \mathrm{Cl} 1.89-64.0, \mathrm{P}=0.004)$.

The optimal timing for predicting survival was further analyzed in three separate regression analyses utilizing different administration windows. TheTocilizumab therapy within the first 24 hours of patient admission was found to be a significant predictor of survival $(\mathrm{OR}=3.86,95 \% \mathrm{Cl}, 1.38-10.8, \mathrm{P}=0.010)$; however, no correlation between tocilizumab therapy and survival rate was found within 48 hours $(\mathrm{P}=$ $0.388)$ or 72 -hours administration window $(P=0.448)$.

The Kaplan-Meier curves display the results of survival analysis for both study groups ( Figure 2). The findings revealed a statistically significant difference supported by the Log-Rank test $(P=0.009)$ and the Wilcoxon test $(P=<0.001)$.

A downtrend in C-reactive protein (CRP) marker within 5 days was observed among 81 (54\%) patients receiving tocilizumab versus $15(6.6 \%)$ control patients based on at least 2 values. The incomplete CRP data with 1 value or less within 5 days from treatment was $60(40 \%)$ in the tocilizumab group compared to $201(89.3 \%)$ in the control group. This outcome was investigated further using a group analysis of matched pairs with a subset of data where CRP levels were available for all three time points $(1,3$, and 5 days) after initiating treatment with tocilizumab or standard of care. This data was available for 16 patients undergoing treatment with tocilizumab and for 9 patients from the control group. Although the mean difference in CRP values between days 3 and 1, days 5 and 1, and days 5 and 3 within the pairs 
were not significantly different between the groups $(P=0.583,0.467$ and 0.114 , respectively), the mean of means was significantly lower for the tocilizumab group $(P=0.002,0.001$ and $<0.001)$.

The data review further revealed the administration of convalescent plasma to $13(8.6 \%)$ patients from the tocilizumab group and $3(1.3 \%)$ patients in the control group. Six (3.6\%) patients from the tocilizumab-treated group and none from the control group received Remdesivir therapy. These data were not included in the analysis considering the lower number of patients and the risk of confounded outcomes.

\section{Biological Analysis}

\section{The Pattern of IL-6 Levels Across Tocilizumab Therapy Patients}

Two patients on tocilizumab therapy developed thromboembolic events on day 5 of their hospital admission (Figure 3). Their IL-6 levels were recorded as $2822.6 \mathrm{pg} / \mathrm{mL}$ and $3000 \mathrm{pg} / \mathrm{mL}$ respectively. The IL-6 levels of five (tocilizumab therapy) patients with thromboembolic events ranged between $77 \mathrm{pg} / \mathrm{mL}$ and $810.4 \mathrm{pg} / \mathrm{m}$ on day 3 of their treatment. The IL-6 levels of two patients with thromboembolic events were recorded as $41.7 \mathrm{pg} / \mathrm{mL}$ and $241.5 \mathrm{pg} / \mathrm{mL}$ on day 1 of their tocilizumab therapy. Six patients on tocilizumab therapy developed thromboembolic episodes, while their IL- 6 levels ranged between $37.6 \mathrm{pg} / \mathrm{mL}$ and $105.8 \mathrm{pg} / \mathrm{mL}$ on day zero of their treatment. Twelve patients with thromboembolism (and selected for tocilizumab therapy) had IL6 levels between $19.7 \mathrm{pg} / \mathrm{mL}$ and $2180.6 \mathrm{pg} / \mathrm{mL}$ on the day of their hospital admission (Figure 3). The findings did not reveal a marked elevation in the IL-6 levels of tocilizumab therapy patients until day 5 of their medical management. The patient data did not reveal a statistically significant correlation between the IL-6 levels of tocilizumab therapy patients and thromboembolic events.

\section{Comparison Between Thromboembolic Events Versus. Deaths Versus. IL-6 Levels of Patients on Tocilizumab Therapy}

Nine out of thirteen tocilizumab therapy patients with thromboembolic events could not survive coronavirus disease and died before hospital discharge. The IL-6 levels of these patients ranged between $19.7 \mathrm{pg} / \mathrm{mL}$ and $2822.6 \mathrm{pg} / \mathrm{mL}$, respectively. The deterministic factors of their death from thromboembolism warrant further investigation. The limited patient data restricted the comparative analysis between mortality, thromboembolic episodes, and IL- 6 levels of the tocilizumab therapy patients. The assessment of the physiological mechanisms dominating the IL- 6 elevation in the tocilizumab therapy patients is out of the scope of this study.

\section{Oxygen Requirements for Mechanically Ventilated Patients on Tocilizumab with Corticosteroid Therapies}

The oxygen requirements for the mechanically ventilated patients on tocilizumab therapy varied considerably between $0.6 \%-100 \%$ until day 5 of their treatment. The high oxygen demand for a few mechanically ventilated patients compared to low-to-moderate oxygen requirements of other patients on MV did not clinically correlate with the administration of tocilizumab therapy. The study did not examine 
external (environmental) or biological (internal) factors impacting the need for mechanical ventilation among the tocilizumab therapy patients.

\section{CRP Levels of Tocilizumab Therapy Patients with Thromboembolic Events}

The study data revealed a marked reduction in the CRP levels of the tocilizumab therapy patients from the date of their admission to the fifth day of treatment. The CRP levels of the tocilizumab therapy patients with thromboembolic events ranged between $93.80 \mathrm{mg} / \mathrm{L}$ to $300 \mathrm{mg} / \mathrm{L}$; however, their CRP levels dropped to $2.90 \mathrm{mg} / \mathrm{L}-187.50 \mathrm{mg} / \mathrm{L}$ on day 5 of their treatment.

\section{Discussion}

In this study of 375 hospitalized patients with COVID-19 disease, treatment with tocilizumab was associated with reduced in-hospital mortality. In addition, the need for MV on days 1, 3, and 5 post-COVID19 treatment was significantly lower in the tocilizumab group. The severity of COVID-19 disease is postulated to be partially driven by hyperactive inflammation and cytokine release syndrome as evidenced by elevated biomarkers such as serum IL-6 and CRP[3]. If left untreated, systemic inflammation leads to hemodynamic instability, multiorgan failure, microvascular thrombosis, and mortality[19]. Several studies have found a beneficial effect of the IL- 6 inhibitor tocilizumab in modulating the hyperactivated immune response of the COVID-19 patients[6, 10,12,18,20]. The results of our study are consistent with the association of tocilizumab with a statistically significant decrease in mortality.

The timing of tocilizumab administration may have an impact on its overall safety and efficacy. The association of tocilizumab administration within the first 48 hours lowered the in-hospital mortality in our study in concordance with the findings of Gupta and colleagues (2020) [12]. the early administration of tocilizumab may benefit COVID-19 patients by attenuating their inflammatory responses mitigating their end-organ damage $[7,18,20]$.

The initial IL- 6 values were lower in the tocilizumab group compared to the control group (a median of 76.1 vs. $142, P=0.01$ ); however, these values may not accurately depict the true IL-6 levels in our control group as only $8 \%$ of patients had a documented IL- 6 level compared to $96.3 \%$ of patients in the treatment group. Nonetheless, the median IL- 6 levels reported in our study are similar to the previously reported IL- 6 levels in COVID-19 patients, which remain lower than the mean peak IL-6 levels in comparative disorders such as acute respiratory distress syndrome and sepsis[2].

The dose of tocilizumab administered was $400 \mathrm{mg}$ in the vast majority of patients reviewed for this study, with only 6 patients receiving a second dose. This intervention occurred before implementing our institution-specific guidelines concerning the use of weight-based dosing (of $8 \mathrm{mg} / \mathrm{kg}$ up to a maximum of $800 \mathrm{mg}$ ) with an optional second dose administered twelve hours later [21]. In critically ill patients, the second dose of tocilizumab is recommended to achieve adequate therapeutic levels[18, 22]. Toniati et al. (2020)[18] used two consecutive intravenous doses of $8 \mathrm{mg} / \mathrm{kg}$ (maximum $800 \mathrm{mg}$ ) twelve hours apart 
and reported significant clinical improvement among COVID-19 patients[18]. Additional studies are warranted to investigate the optimal dosing and frequency of tocilizumab in the setting of COVID-19.

The concomitant therapeutic anticoagulation and corticosteroid use in our study was found to decrease the overall survival of the COVID-19 patients. The patients who received therapeutic anticoagulation were more likely to have a higher disease severity as evidenced by elevated D-dimer and proinflammatory biomarkers compared to those that only received prophylactic dosing. The tocilizumab group had more thromboembolic events than the control group [13 (7.9) vs $9(4 \%), P=0.07]$; however, this finding appears contradictory, given the established procoagulant effect of IL-6 and the demonstrated decrease in factor XIII and prothrombin fragments with tocilizumab[23, 24]. The overall incidence of thromboembolic events may not hold reliability during the study tenure due to the limitation in radiologic studies based on the risk of secondary infection.

The data on corticosteroid use for COVID-19 patients is inconclusive in the medical literature[24]. The RECOVERY trial reported a decrease in 28-day mortality in patients receiving dexamethasone and requiring supplemental oxygen or invasive mechanical ventilation [17]. The use of glucocorticoids was found to be a significant predictor of survival in both the treatment and control groups. However, similar to the patients receiving therapeutic anticoagulation, the decreased odds of survival may likely be a representation of higher severity of illness in those patients selected to receive glucocorticoids during the pandemic.

Contrary to expectations, asthmatic patients have a lower global prevalence of COVID-19 [25, 26]. Our results show that the presence of asthma was an independent predictor of survival of COVID-19 patients. This finding could be explained by the type 2 immune responses involving several cytokines leading to the protective effects of eosinophil accumulation [26]. The angiotensin-converting enzyme 2 (ACE2) receptors are responsible for anchoring the spike proteins of SARS-Cov2, while transmembrane protease serine 2 (TMPRSS2) cleaves the spike protein after invading the cells. The reduced expression of these two receptors in the airway mucosa of the asthmatic patients attributes to their immunocompromised status, type II allergic inflammation, and comorbidities[25, 27]. In addition, the patients with asthma might have presented earlier to receive medical care and started on systemic corticosteroids at the early stages of their disease, which might be beneficial[17].

Our findings are consistent with several retrospective studies suggesting the reduction in MV and mortality after tocilizumab administration, as described by Guaraldi et al. (2020) [11]. Another casecontrol study originating from France shows a reduction in ICU admissions and deaths among patients hospitalized with COVID-19 [28]. Similar data from a multicenter observational study by Biran et al. (2020) [29] support the mortality reduction potential of Tocilizumab for ICU patients admitted with SARSCoV-2 pneumonia. In addition, the patients who received tocilizumab had a decreased requirement for vasopressors compared to control [30]. The STOP-COVID study demonstrated a lower risk of inhospitality mortality in critically ill patients treated with tocilizumab within the first two days of their ICU admission[12]. 
The available data from randomized clinical trials reports conflicting outcomes concerning the therapeutic benefits of tocilizumab therapy. The COVACTA study, a phase III randomized clinical trial, failed to show a reduction in mortality or clinical status improvement after tocilizumab use for 4 weeks. A decrease in the hospital LOS in the tocilizumab cohort was reported, yet deemed insignificant as the primary endpoints were not met [31]. Sarilumab, another II-6 inhibitor, also failed to improve the clinical outcomes across patients on MV after 28 days of hospitalization.41,42 The CORIMUNO randomized clinical trial met its composite primary endpoint of reducing the need for ventilation (either noninvasive or invasive) and mortality within 14 days of hospitalization for moderate-to-severe pneumonia [32. The most recent data from the IMPACT phase III study showed that hospitalized patients who received tocilizumab were $44 \%$ less likely to require MV compared to the placebo group. Their study findings proved statistically insignificant concerning the mortality benefit\{Salama, 2021 \#46]. The BACC study, a multicenter, randomized, double-blind, placebo-controlled, phase-3-trial did not reveal any improvement in mechanical ventilation, clinical course, or mortality until the 28th day of treatment in the setting of COVID19 [33]. Veiga et al.(2019) [34], a small randomized controlled clinical trial did not advocate any benefit in clinical outcomes at 15 days by administering tocilizumab therapy to the critically ill COVID-19 patients. The findings contrarily reported an increase in the mortality rate among the treated patients. The findings of these studies were potentially restricted by their methodology, lack of blinding, insufficient power, and ethnically diverse populations Recently, the RECOVERY trial demonstrated the therapeutic efficacy of tocilizumab therapy in improving the survival rate and other clinical outcomes among COVID-19 patients with hypoxia and systemic inflammation. These benefits increased reciprocally with the concomitant use of systemic corticosteroids [35].

The findings of this study did not confirm a linear correlation between IL-6 level elevation and tocilizumab therapy for COVID-19 patients with thromboembolic events. Our study also did not provide concrete evidence concerning the reduction in IL-6 levels following the administration of tocilizumab to the COVID19 patients. This finding contradicts the systematic review by Kaye et al. (2020) that confirmed the posttreatment benefits of tocilizumab therapy for COVID-19 patients (in terms of) reducing their lymphocytes, neutrophils, CRP, and IL-6 levels[36]. The case study by Michot et al. (2020) confirmed the safety and efficacy of the anti-IL6 receptor antibody (Tocilizumab) in terms of minimizing the risk of respiratory failure in COVID-19 patients. The study also confirmed the IL-6 reduction potential of tocilizumab for immunocompromised COVID-19 patients[37]. The scientific review by Zhang et al. (2020) advocated the IL-6 signal transduction pathway blockade by tocilizumab [38]. Future studies should accordingly investigate the IL- 6 receptor blockade potential of tocilizumab therapy in the context of restricting the classical IL-6 signal in critically ill COVID-19 patients.

This study did not find credible evidence concerning the clinical correlation between thromboembolic events, IL-6 levels, and deaths among patients on tocilizumab therapy, The systematic review and metaanalysis by Pinzon et al. (2021) revealed a strong relationship between IL-6 inhibitor drugs and mortality reduction in the setting of COVID-19 [39]. The findings also revealed the potential of IL-6 inhibitors (including tocilizumab) to minimize the length of hospital stay and mechanical ventilation requirements among the COVID-19 patients on tocilizumab therapy. A retrospective study by Castelnovo et al. (2021) 
confirmed the efficacy of tocilizumab in improving the prognostic outcomes of critically ill COVID-19 patients [40]. The findings further revealed the systemic benefits of tocilizumab concerning the reduction in microvascular complications, inflammatory levels, multiorgan failure, and mortality rate in the setting of COVID-19. Another retrospective study by Rossi et al. (2021) indicated the therapeutic benefits of tocilizumab in minimizing excessive hyper inflammation and mortality rate for COVID-19 patients with pneumonia [41]. The results of a case series by Atallah et al. (2020) contrarily revealed an elevation in the thromboembolic events in the setting of COVID-19 despite the use of anticoagulation, tocilizumab therapy, and a reduction in inflammatory markers [42]. The retrospective study by Capra et al. (2020) revealed the enhancement in the clinical course and survival rate among the COVID-19 patients following the administration of low-dose Tocilizumab[20]. The findings suggested the early use of tocilizumab therapy to effectively improve the COVID-19 prognosis and recovery of the patients with a high risk of the severe acute respiratory syndrome. The current body of evidence does not elaborate on the mechanisms dominating the IL-6 blockade effects of tocilizumab and its potential to inhibit the activity of vascular endothelial cells and coagulation pathways [5]. These contradictions form a strong baseline for future studies warranted to expand current evidence concerning the role of tocilizumab therapy in controlling the mortality rate among COVID-19 patients by reducing their predisposition to IL-6 elevation and thromboembolic episodes.

The findings of our study revealed a marked variation in the oxygen requirements of the mechanically ventilated COVID-19 patients on tocilizumab therapy. The observational study by Niso et al. (2021) supported the potential of tocilizumab therapy in reducing the tissue oxygen demand and elevating the oxygen saturation levels in critically ill COVID-19 patients [43]. The case study by Papamichalis et al. (2020) confirmed the therapeutic benefits of administering tocilizumab with recombinant tissue plasminogen activator in minimizing the respiratory complications of COVID-19 patients [44]. A multicenter retrospective study by Tomasiewicz et al. (2020) affirmed the therapeutic benefit of tocilizumab in terms of minimizing the need for COT (continuous oxygen therapy) for COVID-19 patients within a week of their treatment [45]. The rise in the oxygen saturation levels of the critically ill COVID-19 patients from $90 \%$ to $100 \%$ within 10 days of the first dose of tocilizumab indicates the potential of this drug to enhance the clinical status and minimize the inflammatory response of the patients with COVID19. These results substantiate the requirement of future studies to investigate the role of tocilizumab in minimizing the tissue oxygen demand or elevating the oxygen saturation levels of the COVID-19 patients.

Our study provided evidence concerning the reduction in CRP levels of the COVID-19 patients following the administration of tocilizumab therapy. This finding concords with the outcomes of an observational study by Price et al. (2020) that confirmed the potential of tocilizumab therapy in minimizing the inflammatory processes of cytokine release syndrome-related inflammatory mechanisms by reducing the high-sensitivity C-reactive protein levels in COVID-19 patients [46]. Another single-center experience study by Luo et al. (2020) reported a reduction in CRP levels and subsequent clinical stabilization in COVID-19 patients on tocilizumab therapy [47]. These results strengthen the current evidence concerning the CRP reduction potential of tocilizumab. 


\section{Limitations}

Our study has several limitations that we unequivocally acknowledge. As an observational single-center study, we cannot make any causal inference based on our results and findings that may have been limited due to the incomplete documentation of COVID-19 treatment scenarios in the electronic medical records. The baseline demographics in both groups were similar for age, gender, and BMI, while the race distribution and comorbidities were heterogeneous within the selected groups (with tocilizumab-treated patients having fewer observed chronic medical problems). These differences may have been the result (of selection bias) secondary to the frequency matching used to form the control group.

\section{Conclusions}

Tocilizumab therapy for the management of COVID-19 reduced the in-hospital mortality and the need for MV. The conundrum of tocilizumab-induced IL- 6 blockade in patients with COVID-19 warrants further investigation via a range of case studies and randomized clinical trials. The clinical evidence regarding the potential of tocilizumab to counter IL-6/CRP levels, thromboembolic episodes, mechanical ventilation, and deaths among the COVID-19 patients requires further substantiation for optimizing the multifactorial treatments. The prospective studies should further investigate the utility, dosage, and timing of Tocilizumab for COVID-19 patients. They also need to determine the potential of tocilizumab monotherapy (excluding corticosteroid treatment) in improving the clinical outcomes, prognosis, and recovery of critically ill patients with COVID-19.

\section{Declarations}

Funding: The study was not supported by any funding sources

Conflicts of interest: The authors report no relationships that could be construed as a conflict of interest.

Author Contribution: Dr. Saliaj and Dr. Li had full access to all the data and take responsibility for the integrity of the data and the accuracy of the data analysis to the best of their knowledge.

Concept and design: Saliaj, Li, Salafia, Mantis

Acquisition, analysis, or interpretation of data: All authors

Drafting of the manuscript: Saliaj, Li, Mantis, Rizzo

Critical revision of the manuscript for important intellectual content: All authors

Statistical analysis: Li, Salafia, McMahon,

Acknowledgment: for Administrative, technical, material: Greg McMahon, PhD, Eben Kimbell, MD, Toni Lewis, 
Supervision: Saliaj, Li, Mantis

Deidentified data and related analysis can be provided upon request.

\section{Conflict of interest Disclosure:}

No disclosure to report. The authors declare that they have no known competing financial interests or personal relationships that could have appeared to influence the work reported in this paper

\section{References}

1. Holshue M.L., DeBolt C., Lindquist S., Lofy K.H., Wiesman J., Bruce H., Spitters C., Ericson K., Wilkerson S., Tural A., Diaz G., Cohn A., Fox L., Patel A., Gerber S.I., Kim L., Tong S., Lu X., Lindstrom S., Pallansch M.A., Weldon W.C., Biggs H.M., Uyeki T.M., Pillai S.K., and Washington State -nCo V.C.I.T., First Case of 2019 Novel Coronavirus in the United States. N Engl J Med, 2020. 382(10): p. 929-936 PMID: 32004427; PMC7092802 DOI: 10.1056/NEJMoa2001191.

2. Leisman D.E., Ronner L., Pinotti R., Taylor M.D., Sinha P., Calfee C.S., Hirayama A.V., Mastroiani F., Turtle C.J., Harhay M.O., Legrand M., and Deutschman C.S., Cytokine elevation in severe and critical COVID-19: a rapid systematic review, meta-analysis, and comparison with other inflammatory syndromes. Lancet Respir Med, 2020. 8(12): p. 1233-1244 PMID: 33075298; PMC7567529 DOI: 10.1016/S22132600(20)30404-5.

3. Moore J.B. and June C.H., Cytokine Release Syndrome in Severe COVID 19: Lessons From Arthritis and Cell Therapy in Cancer Patients Point to Therapy for Severe Disease. 2020, WALTER REED NATIONAL MILITARY MEDICAL CENTER BETHESDA MD BETHESDA United States.

4. Cavalli G., De Luca G., Campochiaro C., Della-Torre E., Ripa M., Canetti D., Oltolini C., Castiglioni B., Tassan Din C., Boffini N., Tomelleri A., Farina N., Ruggeri A., Rovere-Querini P., Di Lucca G., Martinenghi S., Scotti R., Tresoldi M., Ciceri F., Landoni G., Zangrillo A., Scarpellini P., and Dagna L., Interleukin-1 blockade with high-dose anakinra in patients with COVID-19, acute respiratory distress syndrome, and hyperinflammation: a retrospective cohort study. Lancet Rheumatol, 2020. 2(6): p. e325-e331 PMID: 32501454; PMC7252085 DOI: 10.1016/S2665-9913(20)30127-2.

5. Mehta P., McAuley D.F., Brown M., Sanchez E., Tattersall R.S., Manson J.J., and Hlh Across Speciality Collaboration U.K., COVID-19: consider cytokine storm syndromes and immunosuppression. Lancet, 2020. 395(10229): p. 1033-1034 PMID: 32192578; PMC7270045 DOI: 10.1016/S01406736(20)30628-0.

6. Fu B., Xu X., and Wei H., Why tocilizumab could be an effective treatment for severe COVID-19? J Transl Med, 2020. 18(1): p. 164 PMID: 32290839; PMC7154566 DOI: 10.1186/s12967-020-02339-3. 
7. Frey N., Cytokine release syndrome: Who is at risk and how to treat. Best Pract Res Clin Haematol, 2017. 30(4): p. 336-340 PMID: 29156206; DOI: 10.1016/j.beha.2017.09.002.

8. De Benedetti F., Brunner H.I., Ruperto N., Kenwright A., Wright S., Calvo I., Cuttica R., Ravelli A., Schneider R., Woo P., Wouters C., Xavier R., Zemel L., Baildam E., Burgos-Vargas R., Dolezalova P., Garay S.M., Merino R., Joos R., Grom A., Wulffraat N., Zuber Z., Zulian F., Lovell D., Martini A., Printo, and Prcsg, Randomized trial of tocilizumab in systemic juvenile idiopathic arthritis. N Engl J Med, 2012. 367(25): p. 2385-95 PMID: 23252525; DOI: 10.1056/NEJMoa1112802.

9. Sheppard M., Laskou F., Stapleton P.P., Hadavi S., and Dasgupta B., Tocilizumab (Actemra). Hum Vaccin Immunother, 2017. 13(9): p. 1972-1988 PMID: 28841363; PMC5612212 DOI: 10.1080/21645515.2017.1316909.

10. Xu X., Han M., Li T., Sun W., Wang D., and Fu B., Effective treatment of severe COVID-19 patients with Tocilizumab.[ChinaXiv: 202003.00026]. 2020, DOI.

11. Guaraldi G., Meschiari M., Cozzi-Lepri A., Milic J., Tonelli R., Menozzi M., Franceschini E., Cuomo G., Orlando G., Borghi V., Santoro A., Di Gaetano M., Puzzolante C., Carli F., Bedini A., Corradi L., Fantini R., Castaniere I., Tabbi L., Girardis M., Tedeschi S., Giannella M., Bartoletti M., Pascale R., Dolci G., Brugioni L., Pietrangelo A., Cossarizza A., Pea F., Clini E., Salvarani C., Massari M., Viale P.L., and Mussini C.,

Tocilizumab in patients with severe COVID-19: a retrospective cohort study. Lancet Rheumatol, 2020. 2(8): p. e474-e484 PMID: 32835257; PMC7314456 DOI: 10.1016/S2665-9913(20)30173-9.

12. Gupta S., Wang W., Hayek S.S., Chan L., Mathews K.S., Melamed M.L., Brenner S.K., Leonberg-Yoo A., Schenck E.J., Radbel J., Reiser J., Bansal A., Srivastava A., Zhou Y., Finkel D., Green A., Mallappallil M., Faugno A.J., Zhang J., Velez J.C.Q., Shaefi S., Parikh C.R., Charytan D.M., Athavale A.M., Friedman A.N., Redfern R.E., Short S.A.P., Correa S., Pokharel K.K., Admon A.J., Donnelly J.P., Gershengorn H.B., Douin D.J., Semler M.W., Hernan M.A., Leaf D.E., and Investigators S.-C., Association Between Early Treatment With Tocilizumab and Mortality Among Critically III Patients With COVID-19. JAMA Intern Med, 2021. 181(1): p. 41-51 PMID: 33080002; PMC7577201 DOI: 10.1001/jamainternmed.2020.6252.

13. Nassar M., Nso N., Alfishawy M., Novikov A., Yaghi S., Medina L., Toz B., Lakhdar S., Idrees Z., Kim Y., Gurung D.O., Siddiqui R.S., Zheng D., Agladze M., Sumbly V., Sandhu J., Castillo F.C., Chowdhury N., Kondaveeti R., Bhuiyan S., Perez L.G., Ranat R., Gonzalez C., Bhangoo H., Williams J., Osman A.E., Kong J., Ariyaratnam J., Mohamed M., Omran I., Lopez M., Nyabera A., Landry I., Iqbal S., Gondal A.Z., Hassan S., Daoud A., Baraka B., Trandafirescu T., and Rizzo V., Current systematic reviews and meta-analyses of COVID-19. World Journal of Virology, 2021. 10(4): p. 182-208 PMID: DOI: 10.5501/wjv.v10.i4.182.

14. Koike R., Harigai M., Atsumi T., Amano K., Kawai S., Saito K., Saito T., Yamamura M., Matsubara T., and Miyasaka N., Japan College of Rheumatology 2009 guidelines for the use of tocilizumab, a humanized anti-interleukin-6 receptor monoclonal antibody, in rheumatoid arthritis. Modern rheumatology, 2009. 19(4): p. 351-357 PMID. 
15. Rosenberg E.S., Dufort E.M., Udo T., Wilberschied L.A., Kumar J., Tesoriero J., Weinberg P., Kirkwood J., Muse A., DeHovitz J., Blog D.S., Hutton B., Holtgrave D.R., and Zucker H.A., Association of Treatment With Hydroxychloroquine or Azithromycin With In-Hospital Mortality in Patients With COVID-19 in New York State. JAMA, 2020. 323(24): p. 2493-2502 PMID: 32392282; PMC7215635 DOI: 10.1001/jama.2020.8630.

16. Paranjpe I., Fuster V., Lala A., Russak A.J., Glicksberg B.S., Levin M.A., Charney A.W., Narula J., Fayad Z.A., and Bagiella E., Association of treatment dose anticoagulation with in-hospital survival among hospitalized patients with COVID-19. Journal of the American College of Cardiology, 2020. 76(1): p. 122-124 PMID.

17. Singh A.K., Majumdar S., Singh R., and Misra A., Role of corticosteroid in the management of COVID-19: A systemic review and a Clinician's perspective. Diabetes Metab Syndr, 2020. 14(5): p. 971-978 PMID: 32610262; PMC7320713 DOI: 10.1016/j.dsx.2020.06.054.

18. Toniati P., Piva S., Cattalini M., Garrafa E., Regola F., Castelli F., Franceschini F., Airo P., Bazzani C., Beindorf E.A., Berlendis M., Bezzi M., Bossini N., Castellano M., Cattaneo S., Cavazzana I., Contessi G.B., Crippa M., Delbarba A., De Peri E., Faletti A., Filippini M., Filippini M., Frassi M., Gaggiotti M., Gorla R., Lanspa M., Lorenzotti S., Marino R., Maroldi R., Metra M., Matteelli A., Modina D., Moioli G., Montani G., Muiesan M.L., Odolini S., Peli E., Pesenti S., Pezzoli M.C., Pirola I., Pozzi A., Proto A., Rasulo F.A., Renisi G., Ricci C., Rizzoni D., Romanelli G., Rossi M., Salvetti M., Scolari F., Signorini L., Taglietti M., Tomasoni G., Tomasoni L.R., Turla F., Valsecchi A., Zani D., Zuccala F., Zunica F., Foca E., Andreoli L., and Latronico N., Tocilizumab for the treatment of severe COVID-19 pneumonia with hyperinflammatory syndrome and acute respiratory failure: A single center study of 100 patients in Brescia, Italy. Autoimmun Rev, 2020. 19(7): p. 102568 PMID: 32376398; PMC7252115 DOI: 10.1016/j.autrev.2020.102568.

19. Ragab D., Salah Eldin H., Taeimah M., Khattab R., and Salem R., The COVID-19 cytokine storm; what we know so far. Frontiers in immunology, 2020. 11: p. 1446 PMID.

20. Capra R., De Rossi N., Mattioli F., Romanelli G., Scarpazza C., Sormani M.P., and Cossi S., Impact of Iow dose tocilizumab on mortality rate in patients with COVID-19 related pneumonia. Eur J Intern Med, 2020. 76: p. 31-35 PMID: 32405160; PMC7219361 DOI: 10.1016/j.ejim.2020.05.009.

21. Bhimraj A., Morgan R.L., Shumaker A.H., Lavergne V., Baden L., Cheng V.C., Edwards K.M., Gandhi R., Muller W.J., O'Horo J.C., Shoham S., Murad M.H., Mustafa R.A., Sultan S., and Falck-Ytter Y., Infectious Diseases Society of America Guidelines on the Treatment and Management of Patients with COVID-19. Clin Infect Dis, 2020 PMID: 32338708; PMC7197612 DOI: 10.1093/cid/ciaa478.

22. Le R.Q., Li L., Yuan W., Shord S.S., Nie L., Habtemariam B.A., Przepiorka D., Farrell A.T., and Pazdur R., FDA Approval Summary: Tocilizumab for Treatment of Chimeric Antigen Receptor T Cell-Induced Severe or Life-Threatening Cytokine Release Syndrome. Oncologist, 2018. 23(8): p. 943-947 PMID: $29622697 ;$ PMC6156173 DOI: 10.1634/theoncologist.2018-0028. 
23. Libby P. and Simon D.I., Inflammation and thrombosis: the clot thickens. 2001, Am Heart Assoc.

24. Guan W.J., Ni Z.Y., Hu Y., Liang W.H., Ou C.Q., He J.X., Liu L., Shan H., Lei C.L., Hui D.S.C., Du B., Li L.J., Zeng G., Yuen K.Y., Chen R.C., Tang C.L., Wang T., Chen P.Y., Xiang J., Li S.Y., Wang J.L., Liang Z.J., Peng Y.X., Wei L., Liu Y., Hu Y.H., Peng P., Wang J.M., Liu J.Y., Chen Z., Li G., Zheng Z.J., Qiu S.Q., Luo J., Ye C.J., Zhu S.Y., Zhong N.S., and China Medical Treatment Expert Group for C., Clinical Characteristics of Coronavirus Disease 2019 in China. N Engl J Med, 2020. 382(18): p. 1708-1720 PMID: 32109013; PMC7092819 DOI: 10.1056/NEJMoa2002032.

25. Jackson D.J., Busse W.W., Bacharier L.B., Kattan M., O'Connor G.T., Wood R.A., Visness C.M., Durham S.R., Larson D., Esnault S., Ober C., Gergen P.J., Becker P., Togias A., Gern J.E., and Altman M.C., Association of respiratory allergy, asthma, and expression of the SARS-CoV-2 receptor ACE2. J Allergy Clin Immunol, 2020. 146(1): p. 203-206 e3 PMID: 32333915; PMC7175851 DOI: 10.1016/j.jaci.2020.04.009.

26. Liu S., Zhi Y., and Ying S., COVID-19 and Asthma: Reflection During the Pandemic. Clin Rev Allergy Immunol, 2020. 59(1): p. 78-88 PMID: 32468411; DOI: 10.1007/s12016-020-08797-3.

27. Wang G., Wu C., Zhang Q., Wu F., Yu B., Lv J., Li Y., Li T., Zhang S., and Wu C. C-Reactive Protein Level May Predict the Risk of COVID-19 Aggravation. in Open Forum Infectious Diseases. 2020. Oxford University Press US.

28. Klopfenstein T., Zayet S., Lohse A., Balblanc J.-C., Badie J., Royer P.-Y., Toko L., Mezher C., Bossert M., and Bozgan A.-M., Tocilizumab therapy reduced intensive care unit admissions and/or mortality in COVID-19 patients. Médecine et Maladies Infectieuses, 2020 PMID.

29. Biran N., Ip A., Ahn J., Go R.C., Wang S., Mathura S., Sinclaire B.A., Bednarz U., Marafelias M., and Hansen E., Tocilizumab among patients with COVID-19 in the intensive care unit: a multicentre observational study. The Lancet Rheumatology, 2020 PMID.

30. Kewan T., Covut F., Al-Jaghbeer M.J., Rose L., Gopalakrishna K.V., and Akbik B., Tocilizumab for treatment of patients with severe COVID-19: A retrospective cohort study. EClinicalMedicine, 2020. 24: $\mathrm{p}$. 100418 PMID: 32766537; PMC7305505 DOI: 10.1016/j.eclinm.2020.100418.

31. Salama C., Han J., Yau L., Reiss W.G., Kramer B., Neidhart J.D., Criner G.J., Kaplan-Lewis E., Baden R., Pandit L., Cameron M.L., Garcia-Diaz J., Chavez V., Mekebeb-Reuter M., Lima de Menezes F., Shah R., Gonzalez-Lara M.F., Assman B., Freedman J., and Mohan S.V., Tocilizumab in Patients Hospitalized with Covid-19 Pneumonia. N Engl J Med, 2021. 384(1): p. 20-30 PMID: 33332779; PMC7781101 DOI: 10.1056/NEJMoa2030340.

32. Review P., Tocilizumab improves significantly clinical outcomes of patients with moderate or severe COVID-19 pneumonia. 2020 PMID. 
33. Stone J.H., Frigault M.J., Serling-Boyd N.J., Fernandes A.D., Harvey L., Foulkes A.S., Horick N.K., Healy B.C., Shah R., Bensaci A.M., Woolley A.E., Nikiforow S., Lin N., Sagar M., Schrager H., Huckins D.S., Axelrod M., Pincus M.D., Fleisher J., Sacks C.A., Dougan M., North C.M., Halvorsen Y.D., Thurber T.K., Dagher Z., Scherer A., Wallwork R.S., Kim A.Y., Schoenfeld S., Sen P., Neilan T.G., Perugino C.A., Unizony S.H., Collier D.S., Matza M.A., Yinh J.M., Bowman K.A., Meyerowitz E., Zafar A., Drobni Z.D., Bolster M.B., Kohler M., D'Silva K.M., Dau J., Lockwood M.M., Cubbison C., Weber B.N., Mansour M.K., and Investigators B.B.T.T., Efficacy of Tocilizumab in Patients Hospitalized with Covid-19. N Engl J Med, 2020. 383(24): p. 2333-2344 PMID: 33085857; PMC7646626 DOI: 10.1056/NEJMoa2028836.

34. Veiga V.C., Prats J.A., Farias D.L., Rosa R.G., Dourado L.K., Zampieri F.G., Machado F.R., Lopes R.D., Berwanger O., and Azevedo L.C., Effect of tocilizumab on clinical outcomes at 15 days in patients with severe or critical coronavirus disease 2019: randomised controlled trial. bmj, 2021. 372 PMID.

35. Horby P.W., Pessoa-Amorim G., Peto L., Brightling C.E., Sarkar R., Thomas K., Jeebun V., Ashish A., Tully R., and Chadwick D., Tocilizumab in patients admitted to hospital with COVID-19 (RECOVERY): preliminary results of a randomised, controlled, open-label, platform trial. Medrxiv, 2021 PMID.

36. Kaye A.G. and Siegel R., The efficacy of IL-6 inhibitor Tocilizumab in reducing severe COVID-19 mortality: a systematic review. PeerJ, 2020. 8: p. e10322 PMID: 33194450; PMC7643559 DOI: 10.7717/peerj.10322.

37. Michot J.M., Albiges L., Chaput N., Saada V., Pommeret F., Griscelli F., Balleyguier C., Besse B., Marabelle A., Netzer F., Merad M., Robert C., Barlesi F., Gachot B., and Stoclin A., Tocilizumab, an anti-IL-6 receptor antibody, to treat COVID-19-related respiratory failure: a case report. Ann Oncol, 2020. 31(7): p. 961-964 PMID: 32247642; PMC7136869 Abbvie, Agios, Amgen, Astex, AstraZeneca, Bayer, Beigene, Blueprint, Bristol-Myers Squibb, Boeringer Ingelheim, Celgene, Chugai, Forma, Genentech, GSK, H3 Biomedecine, Incyte, Innate Pharma, Janssen, Lilly, Loxo, Medimmune, MSD, Novartis, Oncopeptides AB, Roche, Sanofi, Taiho, and Xencor, outside the submitted work, and personal fees or travel grants or adboard: Astex, Iqone, Mundipharma, and Bristol-Myers Squibb, outside the submitted work. BB reports sponsored research at Gustave Roussy Cancer Center with Abbvie, Amgen, AstraZeneca, BeiGene, Blueprint Medicines, BMS, Boehringer Ingelheim, Celgene, Cristal Therapeutics, Daiichi-Sankyo, Eli Lilly, GSK, Ignyta, IPSEN, Inivata, Janssen, Merck KGaA, MSD, Nektar, Onxeo, OSE immunotherapeutics, Pfizer, Pharma Mar, Roche-Genentech, Sanofi, Servier, Spectrum Pharmaceuticals, Takeda, Tiziana Pharma, and Tolero Pharmaceuticals, outside the submitted work. CR reports personal fees for advisory boards from Bristol-Myers Squibb (BMS), Pierre Fabre, Novartis, Amgen, Merck, and Roche, outside the submitted work. FB reports personal fees from AstraZeneca, Bayer, Bristol-Myers Squibb, Boehringer-Ingelheim, Eli Lilly Oncology, F. Hoffmann-La Roche Ltd, Novartis, Merck, MSD, Pierre Fabre, Pfizer, and Takeda, outside the submitted work. AM reports sponsored research at Gustave Roussy Cancer Center with: Abbvie, Aduro, Agios, Amgen, Argen-x, Astex, AstraZeneca, Aveo pharmaceuticals, Bayer, Beigene, Blueprint, BMS, Boeringer Ingelheim, Celgene, Chugai, Clovis, Daiichi Sankyo, Debiopharm, Eisai, Eos, Exelixis, Forma, Gamamabs, Genentech, Gortec, GSK, H3 Biomedecine, Incyte, Innate Pharma, Janssen, Kura Oncology, 
Kyowa, Lilly, Loxo, Lysarc, Lytix Biopharma, Medimmune, Menarini, Merus, MSD, Nanobiotix, Nektar Therapeutics, Novartis, Octimet, Oncoethix, Oncopeptides AB, Orion, Pfizer, Pharmamar, Pierre Fabre, Roche, Sanofi, Servier, Sierra Oncology, Taiho, Takeda, Tesaro, and Xencor, outside the submitted work. DOI: 10.1016/j.annonc.2020.03.300.

38. Zhang C., Wu Z., Li J.W., Zhao H., and Wang G.Q., Cytokine release syndrome in severe COVID-19: interleukin-6 receptor antagonist tocilizumab may be the key to reduce mortality. Int J Antimicrob Agents, 2020. 55(5): p. 105954 PMID: 32234467; PMC7118634 DOI: 10.1016/j.ijantimicag.2020.105954.

39. Pinzon R.T., Wijaya V.O., and Buana R.B., Interleukin-6 (IL-6) inhibitors as therapeutic agents for coronavirus disease 2019 (COVID-19): A systematic review and meta-analysis. J Infect Public Health, 2021. 14(8): p. 1001-1009 PMID: 34153723; PMC8204364 DOI: 10.1016/j.jiph.2021.06.004.

40. Castelnovo L., Tamburello A., Lurati A., Zaccara E., Marrazza M.G., Olivetti M., Mumoli N., Mastroiacovo D., Colombo D., Ricchiuti E., Vigano P., Paola F., and Mazzone A., Anti-IL 6 treatment of serious COVID-19 disease: A monocentric retrospective experience. Medicine (Baltimore), 2021. 100(1): $p$. e23582 PMID: 33429732; PMC7793456 DOI: 10.1097/md.0000000000023582.

41. De Rossi N., Scarpazza C., Filippini C., Cordioli C., Rasia S., Mancinelli C.R., Rizzoni D., Romanelli G., Cossi S., Vettoretto N., Bove S., Manfredini S., Beindorf E.A., Mosca C., Scipione V., Flamminio G., Albini E.A., Giansiracusa P., and Capra R., Early use of low dose tocilizumab in patients with CoVID-19: A retrospective cohort study with a complete follow-up. EClinicalMedicine, 2020. 25: p. 100459 PMID: 32838235; PMC7366117 DOI: 10.1016/j.eclinm.2020.100459.

42. Atallah B., El Nekidy W., Mallah S.I., Cherfan A., AbdelWareth L., Mallat J., and Hamed F., Thrombotic events following tocilizumab therapy in critically ill COVID-19 patients: a Façade for prognostic markers. Thromb J, 2020. 18: p. 22 PMID: 32922212; PMC7479301 DOI: 10.1186/s12959020-00236-9.

43. Di Nisio M., Potere N., Candeloro M., Spacone A., Pieramati L., Ferrandu G., Rizzo G., La Vella M., Di Carlo S., Cibelli D., Parruti G., Levi M., and Porreca E., Interleukin-6 receptor blockade with subcutaneous tocilizumab improves coagulation activity in patients with COVID-19. Eur J Intern Med, 2021. 83: p. 34-38 PMID: 33162299; PMC7608031 DOI: 10.1016/j.ejim.2020.10.020.

44. Papamichalis P., Papadogoulas A., Katsiafylloudis P., Skoura A.L., Papamichalis M., Neou E., Papadopoulos D., Karagiannis S., Zafeiridis T., Babalis D., and Komnos A., Combination of thrombolytic and immunosuppressive therapy for coronavirus disease 2019: A case report. Int J Infect Dis, 2020. 97: p. 90-93 PMID: 32497796; PMC7263262 DOI: 10.1016/j.ijid.2020.05.118.

45. Tomasiewicz K., Piekarska A., Stempkowska-Rejek J., Serafińska S., Gawkowska A., Parczewski M., Niścigorska-Olsen J., Łapiński T.W., Zarębska-Michaluk D., Kowalska J.D., Horban A., and Flisiak R., Tocilizumab for patients with severe COVID-19: a retrospective, multi-center study. Expert Rev Anti Infect Ther, 2021. 19(1): p. 93-100 PMID: 32693650; PMC7441800 DOI: 10.1080/14787210.2020.1800453. 
46. Price C.C., Altice F.L., Shyr Y., Koff A., Pischel L., Goshua G., Azar M.M., McManus D., Chen S.C., Gleeson S.E., Britto C.J., Azmy V., Kaman K., Gaston D.C., Davis M., Burrello T., Harris Z., Villanueva M.S., Aoun-Barakat L., Kang I., Seropian S., Chupp G., Bucala R., Kaminski N., Lee A.I., LoRusso P.M., Topal J.E., Dela Cruz C., and Malinis M., Tocilizumab Treatment for Cytokine Release Syndrome in Hospitalized Patients With Coronavirus Disease 2019: Survival and Clinical Outcomes. Chest, 2020. 158(4): p. 13971408 PMID: 32553536; PMC7831876 DOI: 10.1016/j.chest.2020.06.006.

47. Luo P., Liu Y., Qiu L., Liu X., Liu D., and Li J., Tocilizumab treatment in COVID-19: A single center experience. J Med Virol, 2020. 92(7): p. 814-818 PMID: 32253759; PMC7262125 DOI: 10.1002/jmv.25801.

\section{Tables}

Table 1: Demographics, Baseline Characteristics, Concomitant Therapy 


\begin{tabular}{|c|c|c|c|}
\hline Characteristics & $\begin{array}{c}\text { Tocilizumab } \\
(\mathbf{N}=150)\end{array}$ & $\begin{array}{c}\text { Control } \\
(\mathrm{N}=225)\end{array}$ & $\begin{array}{c}\mathrm{P}- \\
\text { Value }\end{array}$ \\
\hline Median [IQR] age, years & $\begin{array}{c}62.5[53- \\
71]\end{array}$ & $64[54-73]$ & .46 \\
\hline Sex, male & $85(56.7 \%)$ & $125(55.6 \%)$ & .92 \\
\hline Median [IQR] weight, kg & $80.3[68-94]$ & $\begin{array}{c}81.6[70- \\
91.3]\end{array}$ & .83 \\
\hline Median [IQR] BMI & $\begin{array}{l}28.9[25.1- \\
32.9]\end{array}$ & $\begin{array}{l}28.9[26.0- \\
33.9]\end{array}$ & .49 \\
\hline - $\mathrm{BMI}<25$ & $35(23.3 \%)$ & $43(19.1 \%)$ & .43 \\
\hline - BMI $25-30$ & $50(33.3 \%)$ & $66(29.3 \%)$ & .43 \\
\hline - $\mathrm{BMI}>30$ & $55(36.7 \%)$ & $96(42.7 \%)$ & .28 \\
\hline \multicolumn{4}{|l|}{ Race $^{\mathrm{a}}$} \\
\hline - Asian & $8(5.3 \%)$ & $17(7.6 \%)$ & -- \\
\hline - Black & $52(34.7 \%)$ & $105(46.7 \%)$ & -- \\
\hline - Other & $75(50 \%)$ & $79(35.1 \%)$ & -- \\
\hline - Unknown & $9(6.0 \%)$ & $17(7.6 \%)$ & -- \\
\hline - White & $6(4.0 \%)$ & $7(3.1 \%)$ & -- \\
\hline Level of care: intensive care unit & $35(23.3 \%)$ & $72(32 \%)$ & .08 \\
\hline Asthma & $18(12 \%)$ & $26(11.6 \%)$ & 1.0 \\
\hline CAD & $25(16.7 \%)$ & $42(18.7 \%)$ & .68 \\
\hline Cancer & $7(4.7 \%)$ & $19(8.4 \%)$ & .21 \\
\hline $\mathrm{CHF}$ & $4(2.7 \%)$ & $24(10.7 \%)$ & .005 \\
\hline COPD & $5(3.3 \%)$ & $8(3.6 \%)$ & 1.0 \\
\hline Diabetes Mellitus & $58(38.7 \%)$ & $115(51.1 \%)$ & .02 \\
\hline Hypertension & $91(60.7 \%)$ & $150(66.7 \%)$ & .27 \\
\hline Smoking & $3(2.0 \%)$ & $23(10.2 \%)$ & .005 \\
\hline Median [IQR] room air \% O2 saturation & $87[80-94]$ & $89[83-95]$ & .04 \\
\hline $\begin{array}{l}\text { Median [IQR] duration of symptom onset until } \\
\text { hospitalization, days }\end{array}$ & $4[2-7]$ & $5[2-7]$ & .80 \\
\hline
\end{tabular}




\begin{tabular}{|c|c|c|c|}
\hline $\begin{array}{l}\text { Median [IQR] duration of symptom onset until } \\
\text { tocilizumab, days }\end{array}$ & $7[4-11]$ & -- & -- \\
\hline $\begin{array}{l}\text { Tocilizumab administered within } 10 \text { days of } \\
\text { symptom onset }\end{array}$ & $111(74.0 \%)$ & -- & -- \\
\hline $\begin{array}{l}\text { Tocilizumab administered greater than } 10 \text { days } \\
\text { from symptom onset }\end{array}$ & $38(25.3 \%)$ & -- & -- \\
\hline $\begin{array}{l}\text { Median [IQR] time elapsed from admission to } \\
\text { tocilizumab administration, days }\end{array}$ & $1[1-3]$ & -- & -- \\
\hline Median [IQR] WBC (x 103/mcL) & $\begin{array}{l}8.7[6.1- \\
12.0]\end{array}$ & $\begin{array}{l}7.6[5.5- \\
10.1]\end{array}$ & .01 \\
\hline Median [IQR] d-dimer (ng/mL) & $\begin{array}{c}872.0[459- \\
3461.5]\end{array}$ & $\begin{array}{l}884.5[391.5- \\
2444.5]\end{array}$ & .64 \\
\hline Median [IQR] LDH (U/L) & $\begin{array}{c}521.0[402- \\
714]\end{array}$ & $\begin{array}{c}645.0[387- \\
764]\end{array}$ & .41 \\
\hline Median [IQR] IL-6 (pg/mL) & $\begin{array}{l}75.3[46.4- \\
151.3]\end{array}$ & $\begin{array}{c}138.4[74.2- \\
439]\end{array}$ & .02 \\
\hline Median [IQR] AST (U/L) & $\begin{array}{c}51.5[37- \\
84]\end{array}$ & $55[35-79]$ & .86 \\
\hline Median [IQR] ALT (U/L) & $\begin{array}{l}32.0[21- \\
56.5]\end{array}$ & $30[20-47]$ & .20 \\
\hline Median [IQR] ferritin \pm SD & $\begin{array}{c}980.0[579- \\
1466]\end{array}$ & $\begin{array}{l}850[499- \\
2009.5]\end{array}$ & .48 \\
\hline Median [IQR] procalcitonin (ng/mL) & $\begin{array}{l}0.3[0.2- \\
0.6]\end{array}$ & $\begin{array}{l}0.44[0.2- \\
1.4]\end{array}$ & .09 \\
\hline Median [IQR] platelets (x $\left.10^{3} / \mathrm{mcL}\right)$ & $\begin{array}{c}218.0[170- \\
293]\end{array}$ & $\begin{array}{l}193[146- \\
247.5]\end{array}$ & .005 \\
\hline Median [IQR] INR & $\begin{array}{c}1.2[1.1- \\
1.3]\end{array}$ & $1.1[1.1-1.3]$ & .22 \\
\hline Median [IQR] fibrinogen (mg/dL] & $\begin{array}{l}579.0[420- \\
719]\end{array}$ & $\begin{array}{l}634.0[503- \\
665.5]\end{array}$ & .67 \\
\hline Median [IQR] troponin $(\mathrm{ng} / \mathrm{mL})$ & $0[0-0.03]$ & $0[0-0.03]$ & .85 \\
\hline AKI on admission & $45(30.0 \%)$ & $91(40.4 \%)$ & .05 \\
\hline Median [IQR] CRP (mg/L) & $\begin{array}{c}190[122.3- \\
282.4]\end{array}$ & $\begin{array}{c}183.7[117- \\
277.6]\end{array}$ & .67 \\
\hline $\begin{array}{l}\text { Median [IQR] days from symptom onset until } \\
\text { tocilizumab administration }\end{array}$ & $7[4-11]$ & -- & -- \\
\hline Positive radiographic findings on chest imaging & $139(92.7 \%)$ & $202(89.8 \%)$ & .37 \\
\hline Median [IQR] severity level of illness ${ }^{\mathrm{C}}$ & $2[1-2]$ & $2[1-2]$ & .29 \\
\hline Medication & $\begin{array}{c}\text { Tocilizumab } \\
(\mathrm{N}=150)\end{array}$ & $\begin{array}{c}\text { Control } \\
(\mathrm{N}=225)\end{array}$ & $\begin{array}{c}\mathrm{P}- \\
\text { Value }\end{array}$ \\
\hline
\end{tabular}




\begin{tabular}{|c|c|c|c|}
\hline Azithromycin & $138(92.0 \%)$ & $210(93.3 \%)$ & .69 \\
\hline Hydroxychloroquine & $139(92.7 \%)$ & $202(89.8 \%)$ & .37 \\
\hline \multicolumn{4}{|l|}{ Corticosteroids } \\
\hline - Dexamethasone & $24(16.0 \%)$ & $31(13.8 \%)$ & .56 \\
\hline - Methylprednisolone & $38(25.3 \%)$ & $20(8.9 \%)$ & $\begin{array}{c}< \\
.005\end{array}$ \\
\hline - Other & $4(2.7 \%)$ & $4(1.8 \%)$ & .72 \\
\hline \multicolumn{4}{|l|}{ Prophylactic anticoagulation } \\
\hline - Low molecular weight heparin & $68(45.3 \%)$ & $81(36.0 \%)$ & .091 \\
\hline - Unfractionated heparin & $38(25.3 \%)$ & $107(47.6 \%)$ & $\begin{array}{c}< \\
.005\end{array}$ \\
\hline \multicolumn{4}{|l|}{ Therapeutic anticoagulation } \\
\hline - Apixaban & $10(6.7 \%)$ & $6(2.7 \%)$ & .07 \\
\hline - Low molecular weight heparin & $79(52.7 \%)$ & $6(2.7 \%)$ & $\begin{array}{c}< \\
.005\end{array}$ \\
\hline - Unfractionated heparin & $12(8.0 \%)$ & $37(16.4 \%)$ & .02 \\
\hline - Other & $2(1.3 \%)$ & $1(0.4 \%)$ & .57 \\
\hline Ascorbic acid (oral) & $65(43.3 \%)$ & $53(23.6 \%)$ & $\begin{array}{c}< \\
.005\end{array}$ \\
\hline Thiamine & $47(31.3 \%)$ & $45(20.0 \%)$ & .01 \\
\hline Zinc & $77(51.3 \%)$ & $55(24.4 \%)$ & $\begin{array}{c}< \\
.005\end{array}$ \\
\hline
\end{tabular}

Abbreviations: IQR, interquartile range; BMI, body mass index (calculated as weight in kilograms divided by height in meters squared); CAD, coronary artery disease; CHF, congestive heart failure; $\mathrm{COPD}$, chronic obstructive pulmonary disease; $\mathrm{DM}=$ diabetes mellitus; $\mathrm{O}_{2}$, oxygen; WBC, white blood cells; LDH, lactate dehydrogenase; IL-6, interleukin6; SD, standard deviation; AST, aspartate aminotransferase; ALT, alanine aminotransferase; INR, international normalized ratio; AKI, acute kidney injury (defined as serum creatinine $>1.5$ times higher than the baseline or increase of $0.3 \mathrm{mg} / \mathrm{dl}$ ); CRP, Creactive protein.

a Race and ethnicity data were self-reported by patients in prespecified categories.

b Severity level of illness at the time of tocilizumab administration or hydroxychloroquine administration for patients in control group: $0=$ no oxygen requirement; 1 = nasal cannula; $2=$ non-rebreather; $3=$ non-invasive mechanical ventilation; $4=$ mechanical ventilation 
Table 2. Primary and secondary outcomes; logistic regression analysis 


\begin{tabular}{|c|c|c|c|}
\hline Primary and Secondary Outcomes & $\begin{array}{c}\text { Tocilizumab } \\
(\mathrm{N}=150)\end{array}$ & $\begin{array}{l}\text { Control } \\
(\mathrm{N}=225)\end{array}$ & $\mathbf{P}$ - Value \\
\hline In-hospital mortality & $52(25.3 \%)$ & $105(46.7 \%)$ & .0136 \\
\hline \multicolumn{4}{|l|}{ Mechanical ventilation } \\
\hline Day 1 & $13(8.9 \%)$ & $50(22.2 \%)$ & .0005 \\
\hline Day 3 & $12(8.7 \%)$ & $59(27.6 \%)$ & $<.0001$ \\
\hline Day 5 & $19(16.7 \%)$ & $55(32.3 \%)$ & .0021 \\
\hline $\begin{array}{llll}\text { Median }[\mathrm{IQR}] & \text { duration } & \text { of } & \text { mechanical } \\
\text { ventilation, days } & & & \end{array}$ & $8[3-13]$ & $5.5[3-12]$ & .442 \\
\hline Median [IQR] ICU length of stay, days & $9[4-17]$ & $6[3-12.75]$ & .079 \\
\hline Median [IQR] hospital length of stay, days & $10[7-18]$ & $7[4-12]$ & .0002 \\
\hline Thromboembolic complications & $13(8.7 \%)$ & $9(4.0 \%)$ & .0731 \\
\hline $\begin{array}{l}\text { Atrial fibrillation with rapid ventricular } \\
\text { response }\end{array}$ & $5(3.3 \% 0$ & $16(7.1)$ & .170 \\
\hline Positive QuantiFERON & 0 & 0 & -- \\
\hline Injection site reactions & 0 & 0 & -- \\
\hline Anaphylaxis & 0 & 0 & -- \\
\hline \multicolumn{4}{|c|}{ Logistic Regression Results } \\
\hline \multicolumn{4}{|l|}{ Outcome: SURVIVAL } \\
\hline \multicolumn{4}{|c|}{ Entire Cohort $(\mathrm{n}=375)$} \\
\hline Predictor & P-value & \multicolumn{2}{|c|}{$\begin{array}{l}\text { Odds Ratio for Survival } \\
\qquad(95 \% \mathrm{CI})\end{array}$} \\
\hline $\mathrm{RAO}_{2}$ Saturation on Admission & $<.001$ & \multicolumn{2}{|c|}{$1.04(1.02-1.07)$} \\
\hline Steroid Type & .002 & \multicolumn{2}{|c|}{ See text } \\
\hline Therapeutic AC & .006 & \multicolumn{2}{|c|}{ See text } \\
\hline Age (binned) & .019 & \multicolumn{2}{|c|}{ See text } \\
\hline Asthma (Yes) & .022 & \multicolumn{2}{|c|}{$2.61(1.11-6.12)$} \\
\hline Tocilizumab treatment & .026 & \multicolumn{2}{|c|}{$2.10(1.08-4.10)$} \\
\hline DM (Yes) & .064 & \multicolumn{2}{|c|}{$0.61(0.37-1.03)$} \\
\hline Sex (Male) & .083 & \multicolumn{2}{|c|}{$0.63(0.38-1.07)$} \\
\hline \multicolumn{4}{|c|}{ Tocilizumab Group ( $\mathbf{N}=150)$} \\
\hline Predictor & P-value & \multicolumn{2}{|c|}{$\begin{array}{l}\text { Odds Ratio for Survival } \\
\text { (95\% CI) }\end{array}$} \\
\hline Therapeutic AC & .002 & \multicolumn{2}{|c|}{ See text } \\
\hline Steroid Type & .003 & \multicolumn{2}{|c|}{ See text } \\
\hline
\end{tabular}




\begin{tabular}{|c|c|c|}
\hline Asthma (Yes) & .004 & $11.00(1.89-64.04)$ \\
\hline Age (binned) & .007 & See text \\
\hline RAO2 Sat/Admit & .010 & $1.05(1.01-1.10)$ \\
\hline Control Group (N = 225) \\
\hline Predictor to Tocilizumab $(<24$ hrs) & P-value & $\begin{array}{c}\text { Odds Ratio for Survival } \\
\text { (95\% CI) }\end{array}$ \\
\hline $\mathrm{RAO}_{2}$ Saturation on Admission & $<.001$ & $1.07(1.02-1.11)$ \\
\hline Steroid Type & $<.0001$ & See text \\
\hline DM (Yes) & .011 & $0.41(0.23-0.93)$ \\
\hline Age (binned) & .013 & See text \\
\hline Sex (Male) & .044 & $0.49(0.25-0.99)$ \\
\hline Asthma & .067 & $2.68(0.90-7.98)$ \\
\hline
\end{tabular}

Predictor Variables: AC (anticoagulation) prophylaxis, age (binned), Asthma, BMI (Body mass index) (binned), CAD (Coronary artery disease), Cancer, CHF (Congestive heart failure), COPD (Chronic Obstructive Pulmonary Disease), DM (Diabetes mellitus), HTN (hypertension), $\mathrm{RAO}_{2}$ (Room air oxygen), Sex, Steroid Type, Tocilizumab treatment, Therapeutic AC (anticoagulation), Thiamine, Time to Tocilizumab (binned), Vitamin C, Zinc

\section{Figures}




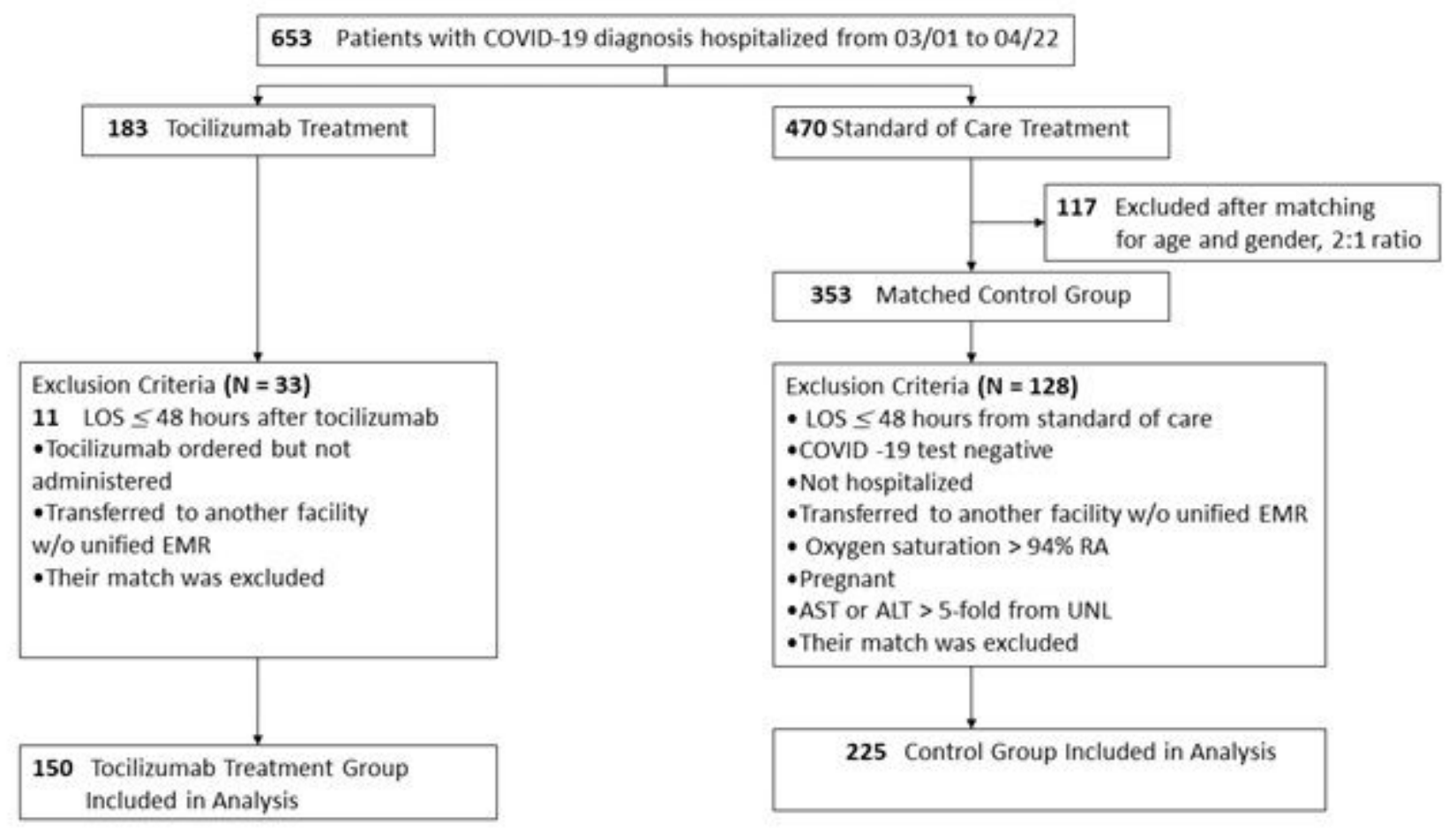

Figure 1

Study Diagram and Flow chart. Abbreviations: AST, aspartate aminotransferase; ALT, alanine aminotransferase; UNL, upper normal limit, EMR, electronic medical record; 02, oxygen; RA, room air

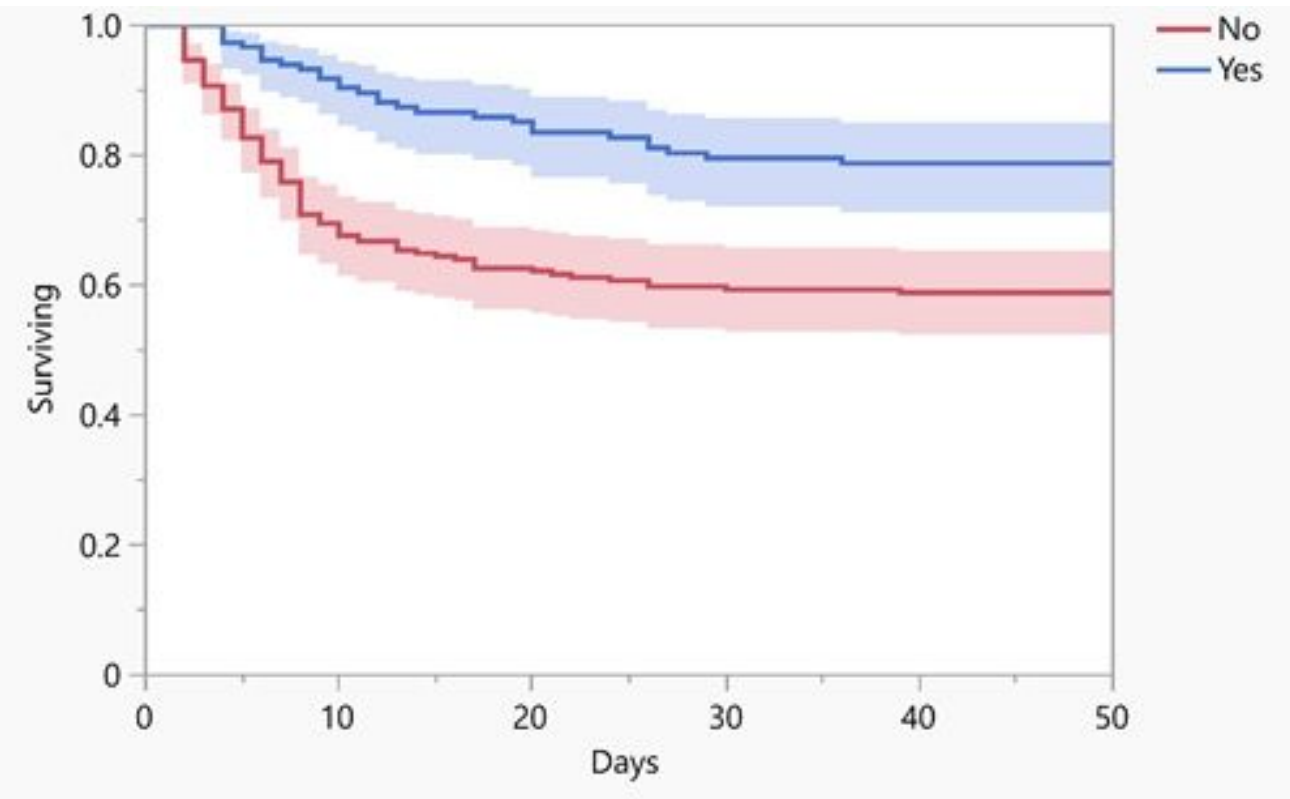

\section{Figure 2}

Kaplan-Meier Survival Curve. Results of survival analysis showing the Kaplan-Meier Curve for the tocilizumab and the control treatment groups. Treatment with tocilizumab results in an overall higher survival rate. 


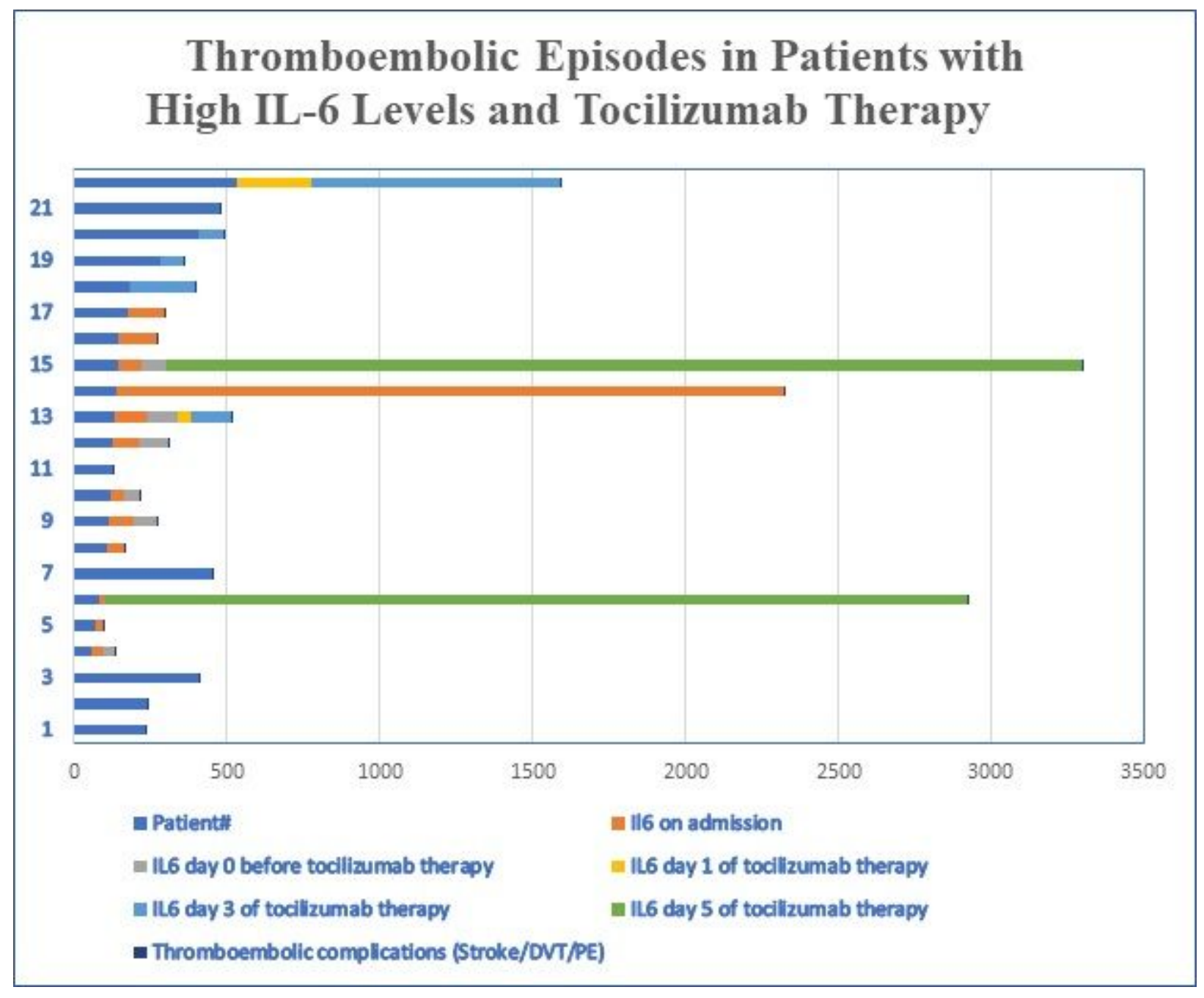

\section{Figure 3}

Thromboembolic Episodes in Patients with High IL-6 Levels and Tocilizumab Therapy. 